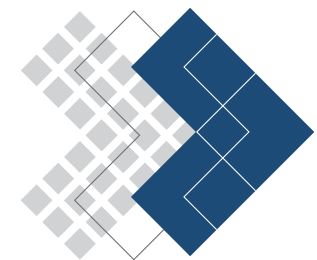 VETOR
}

\section{Seção Especial sobre Energia Nuclear - Apresentação}

\author{
Hermes Alves Filho ${ }^{1}$, Fernando Carvalho da Silva ${ }^{1,2}$ \\ ${ }^{1}$ Instituto Politécnico (IPRJ), Universidade do Estado do Rio de Janeiro, Nova Friburgo, Brasil \\ ${ }^{2}$ Programa de Engenharia Nuclear/COPPE, Universidade Federal do Rio de Janeiro, Rio de Janeiro, Brasil
}

Com a descoberta do nêutron, na década de 1930, um novo ramo de estudos em relação à ciência de partículas foi desenvolvido e aprimorado com o passar dos anos. As partículas neutras foram utilizadas por causar diferentes tipos de transmutações nucleares, e.g., conversão de um elemento químico ou um isótopo em outro elemento. Logo após esta descoberta, tivemos o aparecimento da fissão nuclear, que funcionou como um catalisador para uma crescente era nuclear.

Os nêutrons são partículas nucleares eletricamente neutras, que têm aproximadamente a mesma massa dos prótons. Por sua neutralidade elétrica, podem penetrar mais facilmente em um átomo e interagir com seu núcleo, por meio de ações de espalhamento ou absorção. Por este motivo, atualmente, modelos matemáticos e aplicativos computacionais avançados são desenvolvidos com o objetivo de prever a distribuição de nêutrons em um domínio espacial, para que dessa forma seja possível projetar a proteção de um ambiente pela blindagem dessas partículas, ou, então, a distribuição de potência de um reator nuclear.

Somam-se a isso os atuais problemas energéticos e ambientais, como as mudanças climáticas drásticas, surgindo assim a necessidade de pesquisas e investimentos em fontes de energia "limpas" e economicamente rentáveis, como uma das formas de resolver o problema do aquecimento climático do planeta e revisão da matriz energética usada até agora. As energias renováveis (eólica, solar, biomassa, maremotriz etc.) são apresentadas como a solução do problema energético futuro, mas atualmente esses tipos de fontes de energia não estão ainda disponíveis para assumir uma grande percentagem da geração de energia global, essencialmente por problemas de custos relativamente elevados.

No contexto global, a busca por novas tecnologias e alternativas para produção de energia é incessante. Para atingir as metas e acelerar o crescimento nacional, o Brasil necessita investir fortemente na geração de recursos humanos e no desenvolvimento de alternativas

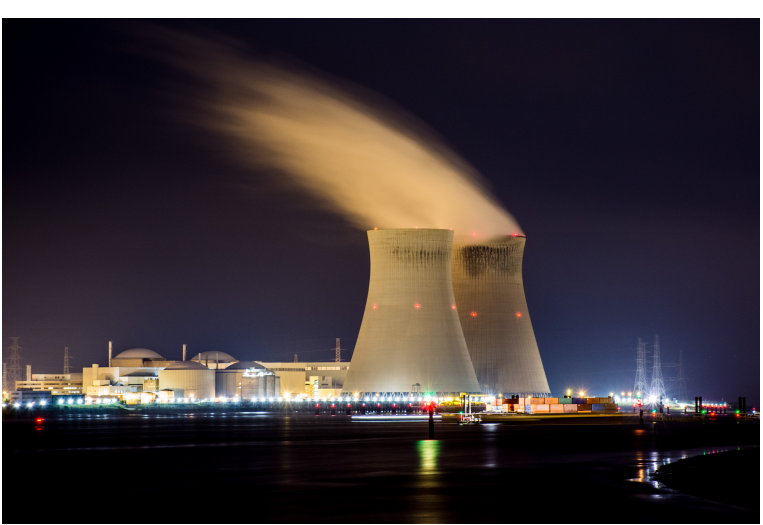

Uma usina nuclear na Bélgica.

Photo by Nicolas HIPPERT on Unsplash para geração de energia. Para que tenhamos, num futuro próximo, uma população mais equilibrada no que diz respeito ao acesso às necessidades básicas e um maior grau de desenvolvimento com responsabilidade pelo nosso planeta, é preciso suprir as necessidades energéticas crescentes dos nossos parques industriais. Deve-se gerar empregos e reduzir o nível de pobreza da população. É necessário procurar por novas tecnologias que possam materializar-se em uma melhoria significativa da qualidade de vida dos cidadãos brasileiros.

No Brasil, grande parte dos recursos hídricos ainda se encontra por explorar; porém, devido à sua enorme extensão territorial e às grandes distâncias dos potenciais hídricos aos grandes centros urbanos, os investimentos em sistemas de transmissão de energia elétrica tornam-se custosos, i.e., as perdas durante as transmissões são signifi- 
cativas e a manutenção onerosa. Para acelerar o crescimento - mantendo um balanço positivo entre a produção e a demanda energética - é preciso diversificar, buscar alternativas para produção de energia que atendam as necessidades dos parques industriais crescentes e que garantam também a preservação ambiental.

Entre os setores produtores de energia, o setor nuclear vem tendo uma participação bastante positiva no balanço energético do país. Hoje, o desenvolvimento de conhecimento científico na área da Engenharia Nuclear tem grande importância não apenas no contexto da produção de energia elétrica, mas também no contexto das vastas aplicações de grande relevância no cenário nacional, e.g., na produção de fármacos, na medicina, na agronomia, na genética, na arqueologia e na aeronáutica.

Neste cenário, afirmamos que a geração de energia elétrica oriunda de usinas nucleares tem se tornado, com o passar dos anos, uma alternativa plenamente viável. Este fato deve-se a três fatores principais:

- a exposição do meio ambiente à radiação gerada em usinas nucleares é muito mais baixa do que aquela causada pelo espectro de outras fontes artificiais, sendo apenas cerca de $1 \%$ da exposição proveniente de radiação natural. Considerando que as usinas nucleares em operação normal não exercem impacto negativo significativo sobre o meio ambiente, pois não emitem poluentes químicos, nem queimam combustíveis fósseis, elas se incluem entre as centrais termoelétricas mais aceitáveis do ponto de vista ecológico durante a operação. Deve ser ressaltado, neste ponto, que uma preocupação mundial atual relaciona-se com o fenômeno do aquecimento global, que tem gerado muitos prejuízos econômicos em vários países do mundo, principalmente nos países desenvolvidos ou em desenvolvimento (considerados emergentes). Iniciativas internacionais, como o Tratado de Kioto, procuram reduzir tais emissões pelos países signatários, visando minimizar a possibilidade de alterações climáticas de consequências econômicas e sociais catastróficas;

- o conteúdo energético de um quilograma de combustível nuclear é muitas vezes maior do que aquele da mesma massa de carvão ou óleo combustível. Um combustível nuclear contendo 3,1\% de urânio físsil (U-235), por exemplo, produz, aproximadamente, 80.000 vezes a energia produzida pela mesma quantidade de carvão mineral. O baixo consumo de combustível nos reatores nucleares, em termos de massa, significa que os custos de combustível representam apenas cerca de uma quarta parte dos custos totais de geração. Consequentemente, os custos de geração de energia elétrica das usinas nucleares são relativamente pouco influenciados pelos aumentos do preço do combustível nuclear;

- os reatores nucleares a água pressurizada (PWR), e.g., Angra I, Angra II e futuramente Angra III, distinguem-se por sua elevada confiabilidade operacional, conforme demonstram os dados disponíveis das usinas nucleares em operação. As extraordinárias características de segurança consideradas no projeto dos reatores PWR, a utilização de peças e componentes que foram experimentados e aprovados em operação durante muitos anos e a minuciosa garantia da qualidade aplicada mediante múltiplos e distintos procedimentos de ensaios, são as principais razões para sua confiabilidade e disponibilidade elevadas.

Segundo o Plano Nacional de Energia 2030 (PNE-2030) haveria a necessidade de construção no Brasil de pelo menos mais quatro usinas nucleares nos próximos anos, mesmo contando com o funcionamento de Angra 3. Existe a possibilidade de construção de até oito novas usinas, com capacidade de gerar $1.000 \mathrm{MW}$ elétricos por central construída. Com isso, a participação da energia nuclear na matriz energética nacional poderá atingir um patamar expressivo de 5,6\%. Outro dado de importância é que o Brasil possui a sexta maior reserva de urânio do mundo, com somente um terço do seu manancial explorado e, além disso, conhecemos a tecnologia do ciclo do combustível, o que torna possível a auto-suficiência na produção do próprio combustível nuclear.

Podemos afirmar que dos avanços na ciência nuclear no século XX, a energia nuclear veio como uma alternativa energética viável aos combustíveis fósseis já utilizados desde o início da prospecção do petróleo, podendo também ser aplicada em diversas áreas do conhecimento, podendo ser citadas:

1. Esterilização;

2. Conservação de Alimentos;

3. Aplicação na Indústria;

4. Ensaios Não-Destrutivos;

5. Segurança Pública (neutrongrafia);

6. Medicina Nuclear (imagens, diagnósticos e terapias).

Por isso, pode-se afirmar que tanto a energia contida nos núcleos dos átomos quanto a radiação que alguns destes núcleos atômicos emitem podem ser úteis para a humanidade; basta que saibamos utilizá-las com responsabilidade e atenção. 
Tendo em conta o cenário descrito, consideramos muito importante a publicação de uma Seção Especial dedicada à Energia Nuclear na Vetor - Revista de Ciências Exatas e Engenharias. Tal Seção contempla estudos de diversas instituições do Brasil e do exterior, que por sua vez abordam uma série de aspectos importantes relacionados à Energia Nuclear.

No trabalhado intitulado "Testes de aderência aplicados à distribuição da profundidade de trinca em tubos do gerador de vapor de uma planta nuclear PWR”, Francisco e Simões avaliam um modelo de distribuição de probabilidade que melhor se ajustou à profundidade das trincas detectadas na inspeção periódica em tubos do gerador de vapor numa planta nuclear do tipo PWR (Pressurized Water Reactor).

Acosta Martínez et al., em “Thermo-Hydraulic Simulation of AP1000 Nuclear Reactor Fuel Assembly”, analisam o comportamento termohidráulico de reatores PWR de terceira geração, empregando um modelo computacional de fluidodinâmica computacional, levando em consideração a interação nêutron-termohidráulica.

No trabalho "Metodologia Espectro-Nodal Determinística para Cálculos de Blindagem de Nêutrons usando a Equação de Equação de Transporte Multigrupo Bidimensional na Formulação das Ordenadas Discretas (SN)", Oliva e Alves Filho apresentam os mais recentes resultados numéricos de uma abordagem nodal (malha grossa), que resultou no desenvolvimento de um novo método da classe dos espectro-nodais, na formulação determinística das ordenadas discretas (SN), aplicado no cálculo de transporte de nêutrons multigrupo, considerando problemas de blindagem (fonte-fixa).

Betancourt et al., no trabalho "Modelo Computacional Neutrônico Baseado no Código Serpent para a Simulação do Núcleo de um Reator Nuclear do Tipo iPWR", descrevem um modelo computacional neutrônico, baseado no código Monte Carlo Serpent, para o projeto de um ciclo de combustível estendido de quatro anos, para reatores integrais de água pressurizada (iPWR).

A aplicação de um método da classe dos espectronodais (malha grossa) na solução de problemas de blindagem de nêutrons em geometria unidimensional nas formulações de ordenadas discretas e multigrupo de energia foi apresentada por Libotte et al. em "Avanços Recentes na Aplicação de um Método Numérico Espectronodal para Solução de Problemas Unidimensionais de Blindagem de Nêutrons".

Finalmente, o trabalho de Kappel et al., intitulado "Novel Approaches on Reactor Core Design Optimization Problem" aborda o emprego de diferentes metaheurísticas - como a Invasive Weed Optimization e a Many-Objective Evolutionary Algorithm na otimização do projeto do núcleo de um reator, com auxílio do código Hammer.

Esperamos, com a publicação dessa Seção Especial na Vetor, ter mostrado para a comunidade científica como um todo a importância do investimento em pesquisa na área nuclear, que vem, com o passar do tempo, agregando um vasto conhecimento e gerando energia mais limpa para o mundo do século XXI. 